\title{
Prevalence of Pregnancy Induced Hypertension among the Pregnant Women: A Study in Shaheed Ziaur Rahman Medical College Hospital, Bogura, Bangladesh
}

\author{
Muhammad Mahmudul Haque ${ }^{1 *}$, Nitai Chandra Sarkar ${ }^{2}$ \\ ${ }^{1}$ Assistant Professor, Department of Anaesthesiology and ICU, Shaheed Ziaur Rahman Medical College \& Hospital, Bogura, Bangladesh \\ ${ }^{2}$ Associate Professor \& Head, Department of Anaesthesiology and ICU, Shaheed Ziaur Rahman Medical College \& Hospital, Bogura, Bangladesh
}

DOI: $10.36348 /$ sjmps.2020.v06i01.009

| Received: 26.12.2019 | Accepted: 04.01.2020 | Published: 17.01.2020

*Corresponding author: Muhammad Mahmudul Haque

\section{Abstract}

Background: Hypertensive disorders in pregnancy is one of the major causes of maternal and neonatal morbidity, mortality, premature birth, intrauterine growth retardation (IUGR), and low birth weight and solely maternal mortality is account for 10-15\% of maternal deaths in developing countries. Each year, an estimated 2.9 million babies die during the neonatal period and 2.6 million babies are stillborn around the world due to presence of PIH in pregnancy. According to WHO 2018, the rate of stillbirth is 21.9 per 1000 births in women with a pregnancy induced hypertension (PIH). The objectives of the study is to estimate the prevalence of pregnancy induced hypertension during pregnancy in a selected rural health center in Bangladesh. Methods \& Materials: A descriptive cross sectional study was carried out and a semistructured questionnaire was used to capture demographic data, obstetric history and on PIH status. The study was conducted from June 2019 to November, 2019. The 80 pregnant women with on or above 20 weeks of gestation admitted in the Shaheed Ziaur Rahman Medical College Hospital, Bogura, Bangladesh or who sought outdoor service were enrolled in the study through purposive sampling technique who met the inclusion criteria. Data on PIH was extracted based on hypertension with on or above systolic and diastolic blood pressure $140 \mathrm{mmHg}$ and $90 \mathrm{mmHg}$ respectively and presence of anemia, oedema, vertigo, sudden weight gain, insomnia and oliguria throughclinical examination and measuring blood pressure (BP) using predesigned and pretested questionnaire. Results: The mean age of the women was found to have24.72 ( \pm SD). The prevalence of Pregnancy Induced Hypertension $(\mathrm{PIH})$ was found $7 / 80 \times 100=8.75 \%$. More than $57 \%$ of PIH was mild, followed by around $29 \%$ and $14 \%$ of PIH were moderate and severe respectively. History of hypertension, LUCS (The lower uterine segment cesarean section), abortion and stillbirth were found 5 (6.25\%), $17(21.25 \%), 21(26.25 \%)$ and $13(16.25 \%)$ respectively. Seven out of 80 pregnant women were found to have hypertension with the presence of anemia, oedema, vertigo, sudden weight gain, insomnia and oliguria. Conclusion: Being a rural health center the prevalence study stands $8.75 \%$ which is most usual. In developing countries it is near about $10-15 \%$. Worldwide the ranges vary from 5-8\%. The study reveals that among the patients with PIH- Most are Primi, Age varies form 18-25 years. They are of low socio economic status and poorly educated.

Keywords: PIH (Pregnancy Induced Hypertension), SDG (Sustainable Development Goal), LUCS (Lower uterine caesarian sections), IUGR (Intra Uterine Growth Retardation).

Copyright @ 2020: This is an open-access article distributed under the terms of the Creative Commons Attribution license which permits unrestricted use, distribution, and reproduction in any medium for non-commercial use (NonCommercial, or CC-BY-NC) provided the original author and source are credited.

\section{INTRODUCTION}

Hypertensive disorders in pregnancy (HDP) refers to a group of conditions associated with high blood pressure during pregnancy. Hypertension in pregnancy involves systolic and diastolic BP with on or above $140 \mathrm{mmHg}$ and $90 \mathrm{mmHg}$ respectively. The preeclampsia and eclampsia are the most serious consequences resulting from PIH (pregnancy induced hypertension). Hypertensive disorders in pregnancy is one of the major causes of maternal and neonatal morbidity, mortality, premature birth, intrauterine growth retardation (IUGR), and low birth weight [1-3] and solely maternal mortality is account for $10-15 \%$ of maternal deaths in developing countries [4]. The mothers who have a history of preeclampsia (17.9\%) are at a greater risk than nulliparous women $(5.3 \%)(\mathrm{p}<$ 0.00001 ) [5]. The incidence of maternal hypertensive disorders is found to have about 20.7 million women in 2013 and about $10 \%$ of pregnancies globally are complicated resulting from gestational hypertensive disorder [1]. In the United States, hypertensive disease 
of pregnancy affect about $8 \%$ to $13 \%$ of pregnancies [2]. Each year, an estimated 2.9 million babies die during the neonatal period and 2.6 million babies are stillborn around the world due to presence of PIH in pregnancy. According to WHO 2018, the rate of stillbirth is 21.9 per 1000 births in women with a pregnancy induced hypertension (PIH) and normotensive women 8.4 per 1000 live births in china [6]. Development of hypertensive disorders of pregnancy are found to be associated with an increased risk of developing preeclampsia, the presence of type I diabetes, gestational diabetes and obesity [7]. The likelihood of progression from gestational hypertension to pre-eclampsia may be increased by a prior history of miscarriage [8]. Bangladesh is committed to ending preventable child and maternal deaths by 2030 . This commitment makes the spirit of achieving universal health coverage (UHC) and aligns with the Sustainable Development Goal. To achieve the SDG goal 3.1, Bangladesh has to bring its maternal mortality rate (MMR) declined to 59 from the current level of 170.1 per 100,000 live births [3][9]. However, the prevalence of hypertensive disorder during pregnancy is not welldocumented in Bangladesh. Evidence on case fatality rates of eclampsia is very limited and maternal deaths due to hypertensive disorders in pregnancy are estimated using a proportional mortality model. The objectives of the study is to estimate the prevalence of pregnancy induced hypertension during pregnancy in Bangladesh.

\section{Material AND Methods}

A descriptive cross sectional study was carried out and a semi-structured questionnaire was used to capture demographic data, obstetric history and on PIH status. The 80 pregnant women with on or above 20 weeks of gestation admitted in the Shaheed Ziaur Rahman Medical College Hospital, Bogura, Bangladesh or who sought outdoor service were enrolled in the study through purposive sampling technique who met the inclusion criteria. Data on PIH was extracted based on hypertension with on or above systolic and diastolic blood pressure $140 \mathrm{mmHg}$ and $90 \mathrm{mmHg}$ respectively and presence of anemia, oedema, vertigo, sudden weight gain, insomnia and oliguria throughclinical examination and measuring blood pressure (BP) using predesigned and pretested questionnaire.

\section{Sample Place and Study Design}

We conducted a descriptive cross sectional study to estimate the prevalence of pregnancy induced hypertension among the pregnant women admitted and outdoor patients in Shaheed Ziaur Rahman Medical College Hospital, Bogura, Bangladesh. The study was conducted from June 2019 to November, 2019.
Sample size calculation and sampling procedures

Sample size was calculated using the following formula for the pregnant women to be enrolled into the study:

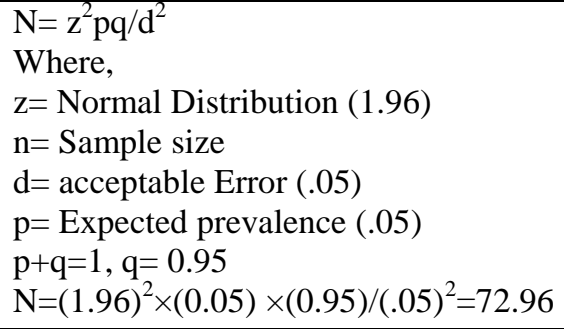

Considering $80 \%$ power, at $5 \%$ level of significance and assuming the prevalence of PIH among pregnant women of $5 \%$, the estimated sample size for the pregnant women was calculated 72.96 , we took 80 to enroll into the study. Participants of the study were enrolled through purposive sampling technique who met the inclusion criteria. The women who were pregnant with on or above 20 weeks of gestation admitted in the Shaheed Ziaur Rahman Medical College Hospital, Bogura, Bangladesh and who sought outdoor service of the same Centre were enrolled as study participants. Data collection technique and quality control. A semi-structured questionnaire was formed to collect the following data related to this study. The data on age, sex, residence, religion, occupation and data related to obstetrical history: gravida, LMP, EDD, abortion, still birth and ALC were collected through face-to-face interview. Data on $\mathrm{PIH}$ was extracted based on hypertension with on or above systolic and diastolic blood pressure140 $\mathrm{mmHg}$ and $90 \mathrm{mmHg}$ respectively and presence of anemia, oedema, vertigo, sudden weight gain, insomnia and oliguria throughclinical examination and measuring blood pressure (BP).

Cause of pregnancy induced hypertension/ Gestational hypertension:

- Unknown

Signs and Symptoms
- High blood pressure
- Headache
- Blurred Vision
- Swelling in extremities
- Nausea
- Fomiting
- Sutigue


Muhammad Mahmudul Haque \& Nitai Chandra Sarkar; Saudi J Med Pharm Sci, Jan., 2020; 6(1): 53-57

\section{Risk Factors}

Maternal Causes

$>$ Obesity

$>$ Mothers under 20 years old mothers over 40 years old

$>$ Past history of DM

$>$ Past history of gestational hypertension

$>$ Past history of renal disease

$>$ Preexisting hypertension Thrombophilia's

\section{Pregnancy}

$>$ Multiple gestation

$>$ Placental abnormalities

\section{Family History}

$>$ Family history of preeclampsia

\section{Treatment}

$>$ There is no specific treatment

$>$ Symptomatic management

$>$ Close monitoring is essential

\section{Data Collection and Analysis}

Data collectors and nurses of the Hospital were dedicated to collect data using a semi-structured questionnaire. Prior to collect data, data collectors received a training for two days on the technique of face-to-face interview with pregnant women, measurement of PIH and objectives of the study. Data collection and Analysis Windows SPSS Version 21.0.

\section{Operational Definition}

Hypertension in pregnancy is defined as the systolic and diastolic blood pressure are on or above systolic and diastolic $140 \mathrm{mmHg}$ and $90 \mathrm{mmHg}$ respectively.

\section{RESULTS}

During the study period, a total of 566 pregnant women did seek pregnancy related service in both indoor and outdoor department of the Shaheed Ziaur Rahman Medical College Hospital, Bogura, Bangladesh. Out of these, we recruited total 80 pregnant women in the study with on or above 20 weeks of gestation. The majority of the participants 46 $(57.50 \%)$ were in the age group of $(18-25)$ years, followed by $22(27.50 \%)$ in (26-30) and $12(15 \%)$ in the age group of (30-35) years. Most of the pregnant women $70(87 \%)$ recruited in the study were Muslim, in contrast; only $10(12.50 \%)$ were Hindu. The primary education of the pregnant women was found to have highest $65(81.25 \%)$; in contrast, illiteracy and higher education were found to have $7(8.75 \%)$ and $8(10 \%)$ respectively. Most of the participants $87.5 \%$ were married after their age of 18 years and more than $81 \%$ of women were housewife.
Table-1: Distribution of demographic characteristics (N=80)

\begin{tabular}{|l|l|l|}
\hline \multicolumn{2}{|c|}{ Characteristics } \\
\hline \multicolumn{2}{|c|}{$\begin{array}{c}\text { Frequency } \\
\text { (n=80) }\end{array}$} & $\begin{array}{l}\text { Percentage } \\
(\%)\end{array}$ \\
\hline Age Group & 46 & 57.50 \\
\hline $18-25$ & 22 & 27.50 \\
\hline $26-30$ & 12 & 15.00 \\
\hline $31-35$ & 70 \\
\hline Religion & 10 & 87.5 \\
\hline Islam & 12.5 \\
\hline Hindu & 8.75 \\
\hline Women's education & 7 & 81.25 \\
\hline Illiterate & 65 \\
\hline Primary & 10 \\
\hline Secondary and above & 8 & 12.5 \\
\hline Age of marriage & 10 & 87.5 \\
\hline Before 18 & 70 & 81.25 \\
\hline On or after 18 & 18.75 \\
\hline Occupation of women & 65 \\
\hline Housewife & 15 \\
\hline Employed &
\end{tabular}

Table-2: Distribution of obstetrical history related data $(\mathbf{N}=\mathbf{8 0})$

\begin{tabular}{|l|c|c|}
\hline \multicolumn{3}{|c|}{ Characteristics } \\
\hline & $\begin{array}{c}\text { Frequency } \\
\text { (n=80) }\end{array}$ & Percentage (\%) \\
\hline Gravida & 30 & 37.50 \\
\hline Primi & 12 & 15.00 \\
\hline Gravida-2 & 22 & 27.50 \\
\hline $\begin{array}{l}\text { Gravida-3 } \\
\text { and above }\end{array}$ & 5 & \\
\hline History of Hypertension \\
\hline Yes & 75 & 6.25 \\
\hline No & 17 & 93.75 \\
\hline History of LUCS \\
\hline Yes & 63 & 21.25 \\
\hline No & 21 & 78.75 \\
\hline History of Abortion \\
\hline Yes & 59 & 26.25 \\
\hline No & 13 & 73.75 \\
\hline History of Stillbirth \\
\hline Yes & 67 & 83.75 \\
\hline No & 73 & 08.75 \\
\hline Pregnancy Induced Hypertension (PIH) \\
\hline Present & 71.25 \\
\hline Absent & 73 & \\
\hline \multicolumn{2}{|c|}{7} \\
\hline
\end{tabular}


Muhammad Mahmudul Haque \& Nitai Chandra Sarkar; Saudi J Med Pharm Sci, Jan., 2020; 6(1): 53-57

Table-3: Presence of signs and symptoms of PIH $(\mathrm{N}=\mathbf{8 0})$

\begin{tabular}{|l|l|l|}
\hline $\begin{array}{l}\text { Presence of } \\
\text { symptoms of PIH }\end{array}$ & $\begin{array}{l}\text { Frequency } \\
(\mathbf{n = 8 0})\end{array}$ & $\begin{array}{l}\text { Percentage } \\
(\%)\end{array}$ \\
\hline Anemia & & \\
\hline Present & 7 & 08.75 \\
\hline Absent & 73 & 91.25 \\
\hline Oedema & & \\
\hline Present & 7 & 08.75 \\
\hline Absent & 73 & 91.25 \\
\hline Vertigo & & \\
\hline Present & 7 & 08.75 \\
\hline Absent & 73 & 91.25 \\
\hline Sudden weight gain & & \\
\hline Present & 7 & 08.75 \\
\hline Absent & 73 & 91.25 \\
\hline Insomnia & & \\
\hline Present & 7 & 08.75 \\
\hline Absent & 73 & 91.25 \\
\hline Olguria & & \\
\hline Present & 7 & 08.75 \\
\hline Absent & 73 & 91.25 \\
\hline
\end{tabular}

Table-4: Classification of PIH (N=80)

\begin{tabular}{|l|l|l|}
\hline $\begin{array}{l}\text { Status of PIH (Based on } \\
\text { diastolic) }\end{array}$ & $\begin{array}{l}\text { Frequency } \\
(\mathbf{n = 7})\end{array}$ & $\begin{array}{l}\text { Percentage } \\
(\%)\end{array}$ \\
\hline Mild (90-100) & 4 & $57.14 \%$ \\
\hline Moderate (101-110) & 2 & $28.57 \%$ \\
\hline Severe (111 and above) & 1 & $14.25 \%$ \\
\hline
\end{tabular}

Among the pregnant women, primi (first pregnancy) were highest $30(37.50 \%)$, followed by gravida-3 and above $22(27.50 \%)$ and gravida-2 12 $(15 \%)$. History of hypertension, LUCS (The lower uterine segment cesarean section), abortion and stillbirth were found $5(6.25 \%), 17(21.25 \%), 21$ $(26.25 \%)$ and $13(16.25 \%)$ respectively. Seven out of 80 pregnant women were found to have hypertension with the presence of anemia, oedema, vertigo, sudden weight gain, insomnia and oliguria. Hence, the prevalence of Pregnancy Induced Hypertension (PIH) was found $7 / 80 \times 100=8.75 \%$. More than $57 \%$ of PIH was mild, followed by around $29 \%$ and $14 \%$ of PIH were moderate and severe respectively.

\section{DiscuSSION}

In this study, history of hypertension was related with enlarged risk of PIH in pregnant women. There is a strong association between previous histories of hypertension and occurrence of PIH in current and the next pregnancy [10]. The study found the estimated prevalence of PIH was $08.75 \%$; which was represented in the previously conducted study in Bangladesh [11]. History of hypertension, LUCS (The lower uterine segment cesarean section), abortion and stillbirth were strongly related to the increased risk of PIH among the women of the study. Previously conducted a study in India, revealed the similar findings [12]. Individual factors such as obesity, multiple gravida or higher age of the mothers were linked with high frequency of PIH. A prospective study was previously conducted; which revealed that effect of obesity among the pregnant women did have 10 times odds of developing PIH [13]. Although this study did not explore the factors linked with PIH the rise in obesity among the women could explain the high prevalence. Another study showed conducted in Zimbabwe, Obesity among women did have increased risk of developing PIH by1.2 \% [14]. The recommendations by the World Health Organisation (WHO) regard to rate of the delivery with caesarean section is between $5 \%$ and $10 \%$. But our study showed much higher rate delivery with caesarean section by $21.25 \%$. According to WHO, caesarean section rates of on or above $15 \%$ are considered to more harmful than usual? Previous study suggests that the more than $15 \%$ of cesarean section rates are linked with enlarged morbidity and mortality for both mothers and babies [15]. Development of PIH in early stage of pregnancy can increase the risk of perinatal mortality in contrast, the cesarean section can decline the risks in women with PIH [16]. A study by Rahman et al discovered that pregnancy induced hypertension was a self-determining risk factor for low birth weight. On the health delivery system, the costs for management of low birth weight was also documented [17]. Hence preventing and/or managing $\mathrm{PIH}$ becomes a priority as one of the ways of reducing the risk of low birth weight and the associated consequences.

\section{CONCLUSION}

Being a rural health center the prevalence study stands $8.75 \%$ which is most usual. In developing country it is near about $10-15 \%$. Worldwide the ranges very from $5-8 \%$. The study reveals that among the patients of PIH- Most are Primi, Age varies form 18-25 years. They are of low socio economic status and poorly educated. To achieve the goals and objectives of MDG and SDG 3.1. Moreover to reduce MMR, IMR and NMR, the reduction of prevalence of PIH is very essential. Perinatal outcome like maternal morbidity/mortality and neonatal death can be prevented with proper antenatal checkup and maternal and fetal close monitoring. Proper attention and close monitoring reduces the risks of complications in pregnancy by early identification and prompt management of problems.

\section{REFERENCES}

1. Misra, P. K., Thakur, S., Kumar, A., \& Tandon, S. (1993). Perinatal mortality in rural India with special reference to high risk pregnancies. Journal of Tropical Pediatrics, 39(1), 41-44.

2. Bai, N. S., Mathews, E., Nair, P. M., Sabarinathan, K., \& Harikumar, C. (1991). Perinatal mortality rate in a south Indian population. Journal of the Indian Medical Association, 89(4), 97-98. 
3. Colglazier, W. (2015). Sustainable development agenda: 2030. Science, 349(6252), 1048-1050.

4. Paul, V. K., \& Singh, M. (2004, April). Regionalized perinatal care in developing countries. In Seminars in Neonatology, 9(2):117124.

5. Kusiako, T., Ronsmans, C., \& Van der Paal, L. (2000). Perinatal mortality attributable to complications of childbirth in Matlab, Bangladesh. Bulletin of the World Health Organization, 78, 621-627.

6. Xiong, T., Mu, Y., Liang, J., Zhu, J., Li, X., Li, J., ... \& Mu, D. (2018). Hypertensive disorders in pregnancy and stillbirth rates: a facility-based study in China. Bulletin of the World Health Organization, 96(8), 531-539.

7. Muti, M., Tshimanga, M., Notion, G. T., Bangure, D., \& Chonzi, P. (2015). Prevalence of pregnancy induced hypertension and pregnancy outcomes among women seeking maternity services in Harare, Zimbabwe. BMC cardiovascular disorders, 15(1), 111.

8. Saudan, P., Brown, M. A., Buddle, M. L., \& Jones, M. (1998). Does gestational hypertension become pre- eclampsia?. BJOG: An International Journal of Obstetrics \& Gynaecology, 105(11), 1177-1184.

9. NIPORT. (2017). Bangladesh - Demographic and Health Survey 2014.

10. Ananth, C. V., \& Basso, O. (2010). Impact of pregnancy-induced hypertension on stillbirth and neonatal mortality in first and higher order births: a population-based study. Epidemiology (Cambridge, Mass.), 21(1), 118-123.
11. Tahmina, H. Z., Shahid, A. R., Hosna, A. U., \& Alam, A. (2014). Study on Outcome of Eclampsia Patients in District Hospital in Bangladesh. Journal of Dhaka Medical College, 23(2), 223-226.

12. Mehta, B., Kumar, V., Chawla, S., Sachdeva, S., \& Mahopatra, D. (2015). Hypertension in pregnancy: A community-based study. Indian Journal Community Med, 40(4):273-278.

13. Bener, A., \& Saleh, N. M. (2013). The impact of socio-economic, lifestyle habits, and obesity in developing of pregnancy-induced hypertension in fast-growing country: global comparisons. Clin Exp Obstet Gynecol, 40(1), 52-57.

14. Steps, N. D. (2005). National Survey Zimbabwe Non-Communicable Disease Risk Factors (ZiNCoDs) Preliminary Report.

15. Chu, K., Cortier, H., Maldonado, F., Mashant, T., Ford, N., \& Trelles, M. (2012). Cesarean section rates and indications in sub-Saharan Africa: a multi-country study from Medecins sans Frontieres. PloS one, 7(9), e44484.

16. Ye, R. W., Liu, Y. H., Ma, R., Ren, A. G., \& Liu, J. M. (2009). Association between pregnancyinduced hypertension, cesarean delivery and perinatal mortality: a prospective study. Zhonghua liu xing bing xue za zhi= Zhonghua liuxingbingxue zazhi, 30(9), 891-894.

17. World Health Organization. (2011). Feto-maternal nutrition and low birth weight. World health Organization, Geneva. Available at: http://www. who. int/nutrition/topics/feto_maternal/en.[Last Accessed on February 23, 2009]. 